\title{
An Electron Microscopic Autoradiographic Study of Proline Incorporation by Mouse Lingual Epithelium*
}

\author{
Donald K. MacCallum and Seong S. Han ** \\ Dental Research Institute Departments of Oral Biology and Anatomy, The University of \\ Michigan
}

Received August 16, 1973

\begin{abstract}
Summary. Mouse lingual epithelium incorporates significant amounts of L-proline-2, $3-\mathrm{H}^{3}$ one hour after intraperitoneal injection of the tritiated amino acid. All viable cell strata incorporated approximately equal amounts of proline as assessed by autoradiographic techniques. Grain counts at 30 minutes, 1 hour, 4 hours and 24 hours, the four time periods studied, indicated a progressive incorporation of proline up to 4 hours following injection. Preferential incorporation of proline into any one cell structure or group of structures was not observed. Keratohyalin granules (KHG's) demonstrated incorporated proline; however, usually only one silver grain appeared over each granule, and, based on grain counts, the amount of proline incorporated by KHG's appeared slightly less than the general labeling observed in KHGcontaining cells. This finding supports recent biochemical studies which have indicated a considerably lower proline content of keratohyalin than had previously been reported. Significant proline incorporation into the epithelial basal lamina was not observed during the 24 hours of this study. Thus, while recent recombination experiments have conclusively demonstrated that epithelial basal cells synthesize considerable quantities of basal lamina in a 24 hour period; it would appear that epithelial basal cells contribute little to a formed, intact basal lamina. This finding lends credence to the concept of a long basal lamina turnover time.

Key words: Proline - Keratohyalin - Basal lamina - Epithelium - Autoradiography.
\end{abstract}

\section{Introduction}

The avascular nature of a complex and metabolically active tissue such as stratified squamous epithelium makes the problems of nutrient distribution to various cell strata and subsequent nutrient utilization particularly important. Amino acids incorporated by stratified squamous epithelial cells, in addition to participating in metabolic functions common to all cells, are utilized in the synthesis of specialized structures such as tonofilaments, keratohyalin granules (KHG's), desmosomes and membrane coating granules (Matolsty and Parakkal, 1967; Listgarten, 1972). An additional specialized function of stratified squamous epithelial basal cells is the synthesis of the basal lamina (Briggaman et al., 1971; Hay and Dodson, 1973). Fukuyama and Epstein (1966) have studied the incorporation pattern of ten different amino acids in newborn rat epidermis using the technique of light microscopic autoradiography. In addition to the notable finding that histidine, serine and arginine were preferentially incorporated by the stratum

\footnotetext{
* Supported by Public Healths Service grants DE 02731, DE 03393

** The authors are grateful to Dr. John H. Lillie for his help in determining blood levels of proline- $\mathrm{H}^{3}$ and to Dr. V. C. Hascall for his advice on isotope selection. Mrs. K. Y. Y. Chen performed nearly all technical matters associated with this study, and made many of the original electron microscopic observations. Her assistance was invaluable.
} 
granulosum, they demonstrated that intraperitoneally delivered amino acids were rapidly available to stratified squamous epithelial cells (Fukuyama et al., 1965; Fukuayma and Epstein, 1966).

We have elected to study proline- $\mathrm{H}^{3}$ incorporation by oral mucosal epithelium using light and electron microscopic autoradiography for a series of reasons: 1) The reported high proline content of keratohyalin granules (Matoltsy and Matoltsy, 1970) has recently been challenged (Tezuka and Freedberg, 1972a; Ugel and Idler, 1972). Therefore, one purpose of this study was to determine whether there was preferential incorporation of proline into keratohyalin. 2) Proline and its hydroxylated derivatives considered together constitute the second most plentiful amino acid recovered from basement membranes (Kefalides, 1973). Therefore, localization of proline could be used to study whether epithelial basal cells contribute extensively to a formed, intact basal lamina. 3) Of the amino acids studied by Fukuyama and Epstein (1966), proline was reported to be initially distributed in an almost equal fashion between the basal, spinous and granular layers. Therefore, proline appeared to be an excellent choice for determining whether marked differences in the incorporation of the amino acid, in a generic sense, occurred between the stratified squamous epithelium of skin and oral mucosa.

\section{Materials and Methods}

Weanling C58 mice (14-17 gm) were injected intraperitoneally with 166 microcuries/gram of L-proline-2, 3- $\mathrm{H}^{3}$ (s.a. $>40 \mathrm{c} / \mathrm{mM}$; New England Nuclear, Boston, Mass. 02118). The proline- $\mathrm{H}^{3}$ was concentrated by flash evaporation and re-dissolved in sterile saline to yield a final injection volume of approximately $0.25 \mathrm{ml}$. The animals were killed by an overdose of ether at 30 minutes, 1 hour, 4 hours and 24 hours after injection. The tongue was removed and sliced into small pieces which were rinsed quickly in $\mathbf{3}$ changes of Eagle's minimum essential medium with Earle's salts (Grand Island Biological Co., Grand Island, New York 14072). Tissues were fixed for 2 hours at $4^{\circ} \mathrm{C}$ in a mixture of $1 \%$ paraformaldehyde and $1 \% \mathrm{OsO}_{4}$ in $0.1 \mathrm{M}$ sodium cacodylate buffer, $\mathrm{pH}$ 7.3. Following a brief buffer rinse, tissues were dehydrated. in ascending concentrations of ethyl alcohol and propylene oxide prior to embedding in Epon.

One micron sections were cut with glass knives and mounted on glass slides. In an attempt to minimize varying results due to differences arising from coating procedures, each slide contained sections from all experimental time periods (12 sections/slide). The slides were dip coated in N'TB-3 emulsion (Eastman Kodak Company, Rochester, New York 14650) and, after appropriate exposure, developed for one minute in D-170 (Eastman Kodak Company) and fixed for 2 minutes in. Rapid Fix (Eastman Kodak Company). The processed slides were stained in $\mathrm{pH} 7.3,1 \%$ toluidine blue 0 , differentiated in an ascending series of ethyl alcohols, cleared in xylene with coverslips being affixed by the use of a synthetic resin. Sections having silver to pale gold interference colors were cut for electron microscopy using a diamond knife. The sections were collected on formvar-coated grids, stained with aqueous uranyl acetate and lead citrate, and subsequently coated by a light layer of evaporated carbon. The loop coating method (Caro and van Tubergen, 1962) was used to apply L-4 emulsion (Ilford, Ltd., Essex, England). Tissues were exposed for 58 days following which they were developed in F-24 (Eastman Kodak Company) for 5 minutes and fixed for 2 minutes in Rapid Fix. A Philips EM-300 electron microscope was used to view and photograph the sections. Most photographs were taken at a magnification of 6000 times and grain counts were made on the negatives with no further enlargement. To establish units of lengths, a map measure (Catalog number 620305, Keuffel and Esser Co., Switzerland) was employed.

In order to determine the availability of the proline- $\mathrm{H}^{3}$ to the lingual epithelium, 100 microliters of mixed arterial and venous femoral blood were collected and added to an equal volume of sodium heparin (Liquaemin Sodium " 10 ", Organon, Inc., W. Orange, N. J.). Proteins were precipitated by the addition of cold $0.5 \mathrm{~N}$ perchloric acid which contained $0.5 \%$ phospho- 


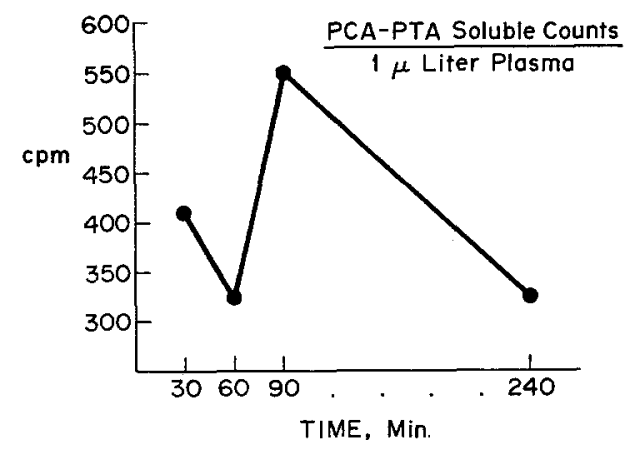

Fig. 1. Proline 2, 3- $\mathrm{H}^{3}$ into lingual epithelium. Blood levels of unincorporated proline- $\mathrm{H}^{3}$ at four time periods. Although the blood level dropped progressively after 90 minutes, there remained a considerable amount of unincorporated proline four hours after injection

tungstic acid. One hundred microliters of the supernatant were added to a toluene-Triton. $\mathrm{X}-100$ scintillation counting fluid. Radioactivity of the supernatant was determined using a Packard Tri-Carb 3320 liquid scintillation spectrophotometer with adjustement for quenching made using an external standard. The results are shown in figure 1.

\section{Results}

The tissue selected for study was the minimally keratinized stratified squamous epithelium immediately contiguous with the specialized dorsal lingual mucosa. The epithelium consisted of approximately 10 layers of nucleated cells and 4 layers of disjunctive, keratinized cells (Fig. 2). A distinctive stratum granulosum was not present. However, keratohyalin granules first appeared in the middle of the stratum spinosum and subsequently increased in both number and size as the spinous cells approached the keratinized layer.

The progress of proline incorporation into the lingual epithelium as monitored by light microscopy revealed a gradual incorporation over the first hour following injection (Figs. 3-4). Isotope incorporation appeared to be approximately equal in all viable cell strata. Both bacteria adhering to the lingual epithelium and a surface coat applied to the surface (cell membrane) adjacent to the oral cavity demonstrated proline incorporation one hour following injection (MacCallum, 1974) Four hours after injection the epithelium was intensely labelled. The innermost layer of disjunctive cells also demonstrated an occasional, heavily labelled cell (Fig. 5). Four hours was also the first of the time periods studied which demonstrated extensive labeling of the lamina propria. Twenty-four hours after proline injection the epithelium demonstrated a reduced, but nevertheless, still conspicuous amount of labeling. The keratinized layer was labelled in its totality (Fig. 6).

As reflected in the light micrographs, there was a progressive increase in the amount of proline incorporated by the epithelial basal cells as observed by electron microscopy. At the four hour time period grains were distributed over both the nucleus and cytoplasm (Fig. 7). Grains were also present over the basal lamina and the cells and extracellular components of the lamina propria. Twenty-four hours after proline injection the amount of labelled proline in the basal cells was reduced and fewer grains appeared over the basal lamina (Fig. 8). The connective tissue 

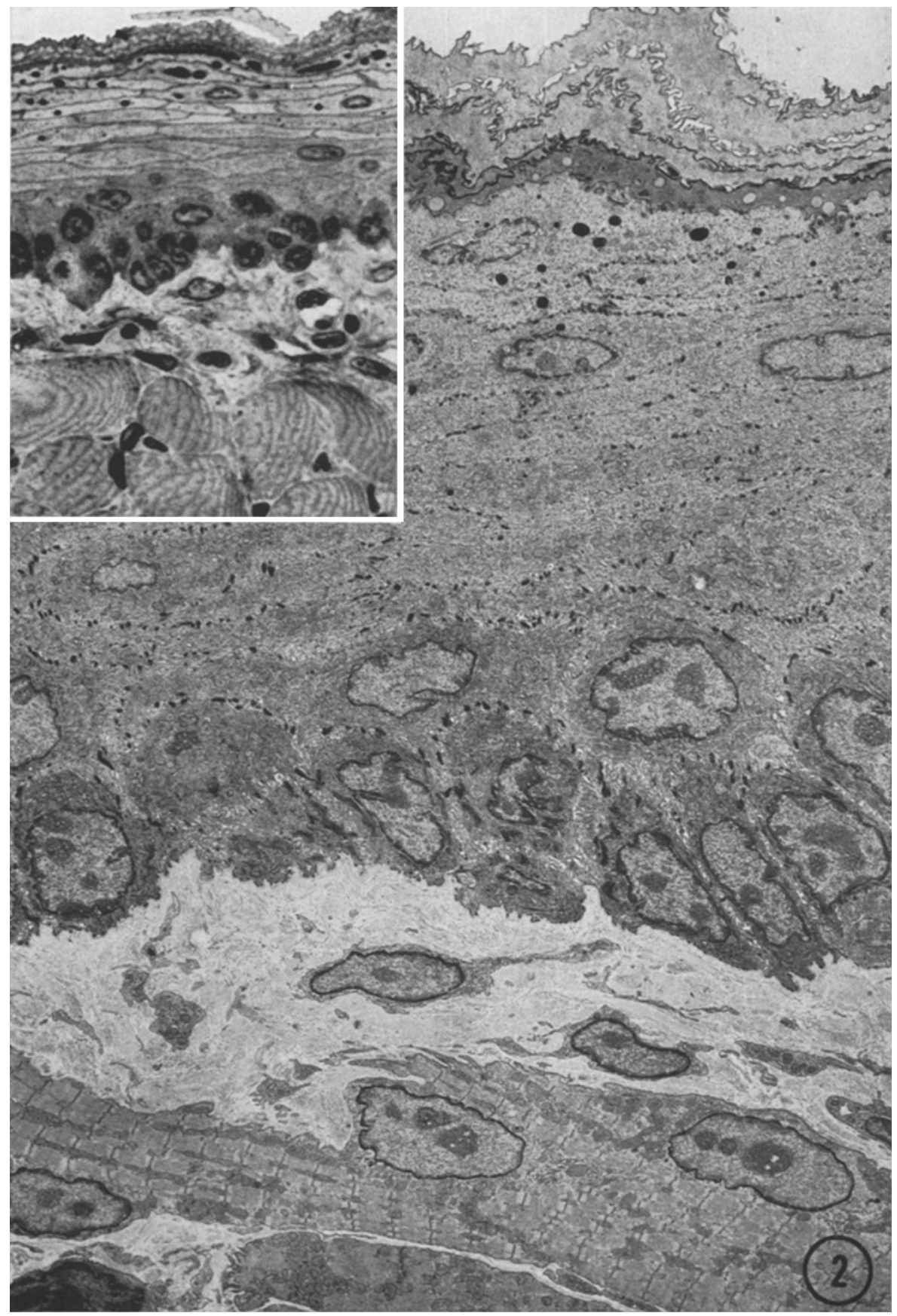

Fig. 2. Survey electron micrograph illustrating morphology of lingual epithelium. Note lamina propria, usually quite thin, and contiguous with tongue musculature. Inset: Light micrograph of this epithelium. $\times 3000$, Inset $: \times 800$ 
demonstrated the continued presence of a large quantity of incorporated proline. Data acquired from grain counts concerning proline incorporation by basal cells as it relates to the synthesis of the basal lamina are presented in Table 1 . The decrease in the amount of labelled proline associated with the basal lamina at twenty four hours, when compared to 4 hours, is very closely related to the overall decrease of labelled proline found in epithelial basal cells (\% grains/random straight line).

Spinous cells demonstrated a gradual increase in the amount of labelled proline contained both within the nucleus and cytoplasm over the four hour period following injection (Fig. 9). There was a progressive increase in the percentage of KHG's labelled over this same time period. Usually, each granule had one silver grain associated with it; however, occasional KHG's demonstrated two grains (Figs. 10, 11). Grain counts reflecting increased incorporation of proline by spinous cells over the four hour period after isotope administration including increased labelling of KHG's are presented in table 2 . Both subjective observations of the labelled proline incorporated into KHG's and grain counts along a random straight line indicated there was no discernible preferential proline incorporation into keratohyalin. Table 2 also presents data relative to the number of grains associated with the edge of spinous cells. The phenomenon of peripherallylocated proline was examined after many micrographs demonstrated a sizeable number of grains associated with spinous cell membranes. However, as the grains were not associated with any particular organelle and, as they did not show any marked percentage variation with time, we could not ascribe any particular significance to this distribution of the labelled amino acid.

The progressive addition of labelled cells to the keratinized layer was easily followed by electron microscopy. One hour following proline injection the keratinized layer was devoid of label except for occasional immediately cells adjacent to the stratum spinosum and a surface coating at the junction of the epithelium with the oral cavity (Fig. 12). Twenty-four hours after proline administration virtually all the keratinized cells were labelled (Fig. 13). The percentage of labelled cells entering the keratinized layer is tabulated in table 2.

\section{Discussion}

Based upon recombination experiments, in many instances using non-viable substrates, current evidence would indicate that certain epithelia including stratified squamous epithelium can synthesize their own basal laminae (Briggaman et al., 1971; Cohen and Hay, 1971; Hay and Dodson, 1973). Our study indicates that once the basal lamina is formed, the epithelial contribution to it is at a very low level. This conclusion is based upon our findings that grains representing proline- $\mathrm{H}^{3}$ associated with the basal lamina reflected directly the percentage of grains (incorporated proline- $\mathrm{H}^{3}$ ) of basal cells. Thus, the lack of a disproportionally higher number of basal lamina-associated grains when compared against the number of grains in the basal cell cytoplasm at either the four or twenty-four hour period would put the epithelial basal cell's contribution to the basal lamina below the sensitivity of the techniques employed in this study. The stability of the basal lamina has been indicated by a number of experiments which are discussed by Ross and Grant (1968). These investigators also demonstrated the per- 

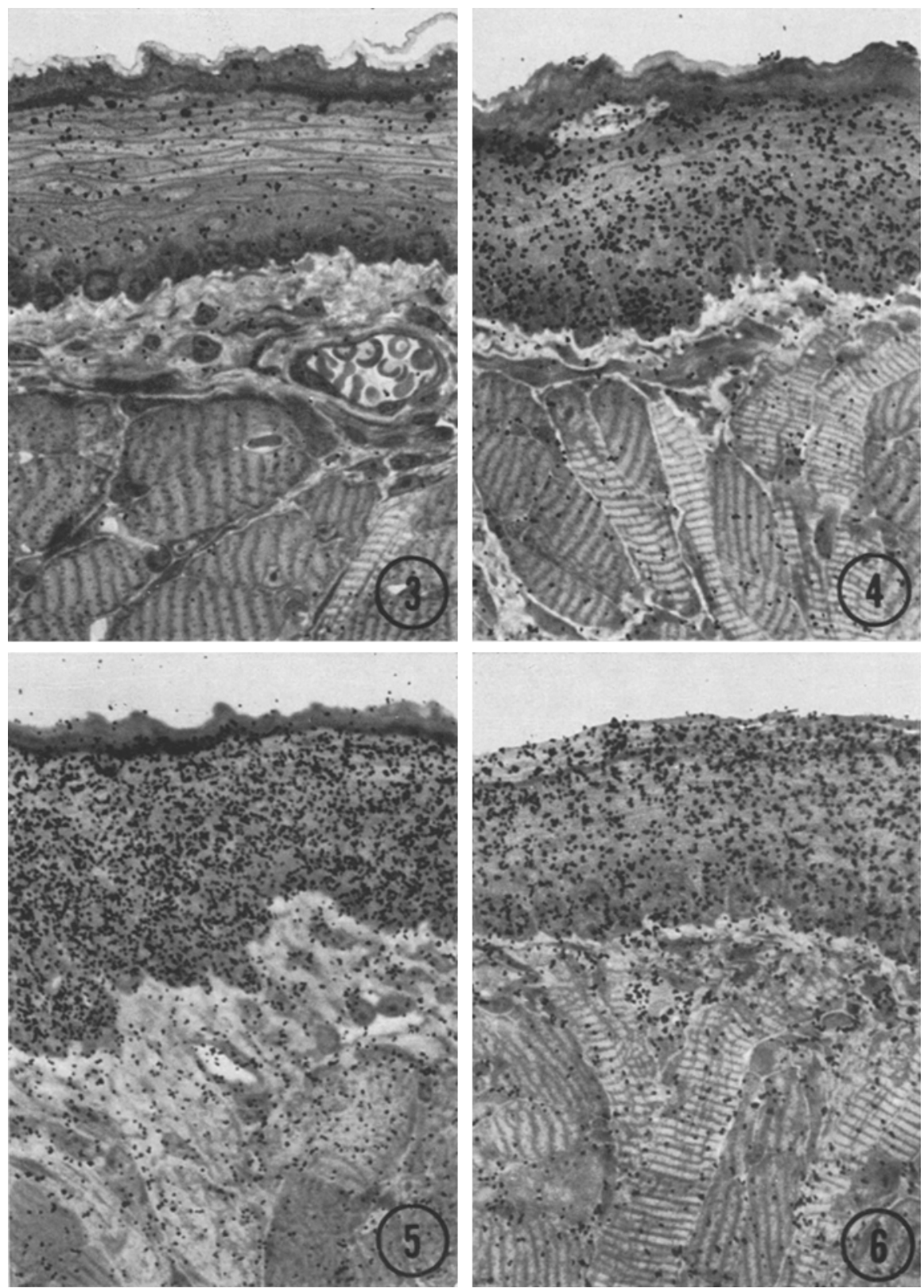

Fig. 3. Light microscopic autoradiograph 30 minutes following proline- $\mathrm{H}^{3}$ injection. Toluidine blue $0 . \times 450$

Fig. 4. Light microscopic autoradiograph 1 hour following isotope injection; proline- $\mathrm{H}^{3}$ present in approximately equal amount in all viable cell strata. Surface labeling of epithelium due to proline- $\mathrm{H}^{3}$ containing bacteria. Toluidine blue $\mathrm{O} . \times 450$

Fig. 5. Light microscopic autoradiograph 4 hours after proline- $H^{3}$ Injection. Epithelium very heavily labelled. Lamina propria also demonstrates moderate degree of proline- $\mathrm{H}^{3}$ incorporation. Toluidine blue $0 . \times 450$ 
Table 1

\begin{tabular}{|c|c|c|}
\hline \multirow[t]{2}{*}{ Time } & Percent grains & Percent grains \\
\hline & Basal Lamina ${ }^{a}$ & Random straight Line ${ }^{a}$ \\
\hline $4 \mathrm{~h}$ & $69\left[\frac{71}{103}\right]$ & $70\left[\frac{52}{74}\right]$ \\
\hline $24 \mathrm{~h}$ & $32\left[\frac{39}{122}\right]$ & $30\left[\frac{22}{74}\right]$ \\
\hline
\end{tabular}

a Arbitrary units of lengths made by map measuring device.

Table 2

\begin{tabular}{lcccc}
\hline Time & $\begin{array}{c}\text { \% keratohyalin } \\
\text { granules labeled }\end{array}$ & $\begin{array}{l}\text { \% grains random } \\
\text { straight line }\end{array}$ & $\begin{array}{l}\text { \% Edge touch vs } \\
\text { total grains }\end{array}$ & $\begin{array}{c}\text { \% Disjunctive } \\
\text { cells labeled }\end{array}$ \\
\hline $30 \mathrm{~min}$ & $18\left[\frac{60}{320}\right]$ & $25\left[\frac{15}{60}\right]$ & $29\left[\frac{183}{621}\right]$ & 0 \\
$1 \mathrm{~h}$ & $38\left[\frac{51}{133}\right]$ & $58\left[\frac{44}{76}\right]$ & $25\left[\frac{80}{316}\right]$ & $10\left[\frac{4}{40}\right]$ \\
$4 \mathrm{~h}$ & $68\left[\frac{110}{160}\right]$ & $73\left[\frac{56}{76}\right]$ & $29\left[\frac{618}{2156}\right]$ & $30\left[\frac{18}{59}\right]$ \\
$24 \mathrm{~h}$ & $12\left[\frac{50}{432}\right]$ & $24\left[\frac{146}{602}\right]$ & $97\left[\frac{109}{112}\right]$ \\
\hline
\end{tabular}

a In keratohyalin granule-containing cells.

b Grains at junction of oral cavity and stratum disjunctivum not counted.

sistence of rat seminiferous tubular basal laminae following involution of these structures subsequent to hypophysectomy. Similarly, Parakkal (1969) has demonstrated the persistence of the hair follicle outer root sheath basal lamina following death of the outer root sheath cells. This residual basal laminar material was present during the catagen phase of the hair growth cycle and subsequently disappeared during the telogen phase. Walker (1972) used dark field microscopy to study the time course for the disappearance of silver from the basal laminae of argyric rats. He found the silver disappeared from various basal laminae at different rates: colon, 6 weeks; glomerular basal laminae, 6 months; hair follicle, 2.5 years. Thus different basal laminae are degraded and resynthesized at different

Fig. 6. Light microscopic autoradiograph 24 hours after proline- $\mathrm{H}^{3}$ administration. All viable cell strata still retain considerable amount of proline- $\mathrm{H}^{3}$. The keratinized layer is completely labelled. The muscle cells have incorporated very little proline- $\mathrm{H}^{3}$; most grains are localized in connective tissue of endomysium. Of 3 tissues (epithelium, connective tissue, muscle) studied, epithelium conspicuously incorporated greatest amount of proline- $\mathrm{H}^{3}$. Toluidine blue $0 . \times 450$ 

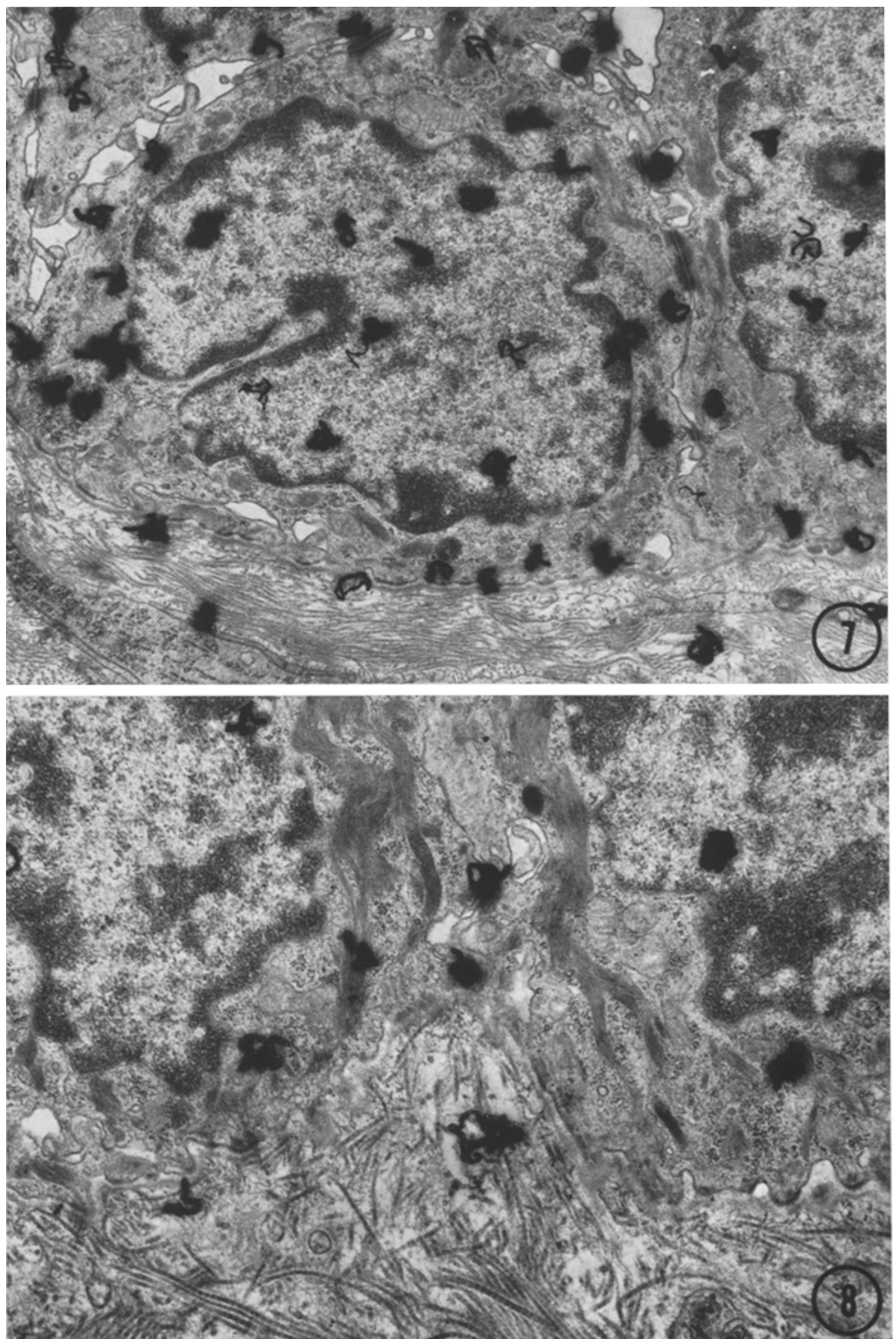

Fig. 7. EM autoradiograph of epithelial basal cell 4 hours after proline- $\mathrm{H}^{3}$ administration. Note grains in basal cell, basal lamina, and lamina propria. $\times 10000$

Fig. 8. EM autoradiograph of epithelial basal cell 24 hours after proline administration.

Reduced amount of proline- $\mathrm{H}^{3}$ in basal cells and very little label associated with basal lamina. Although not shown in this micrograph, connective tissue of lamina propria demonstrated considerable labeling. $\times 10000$ 

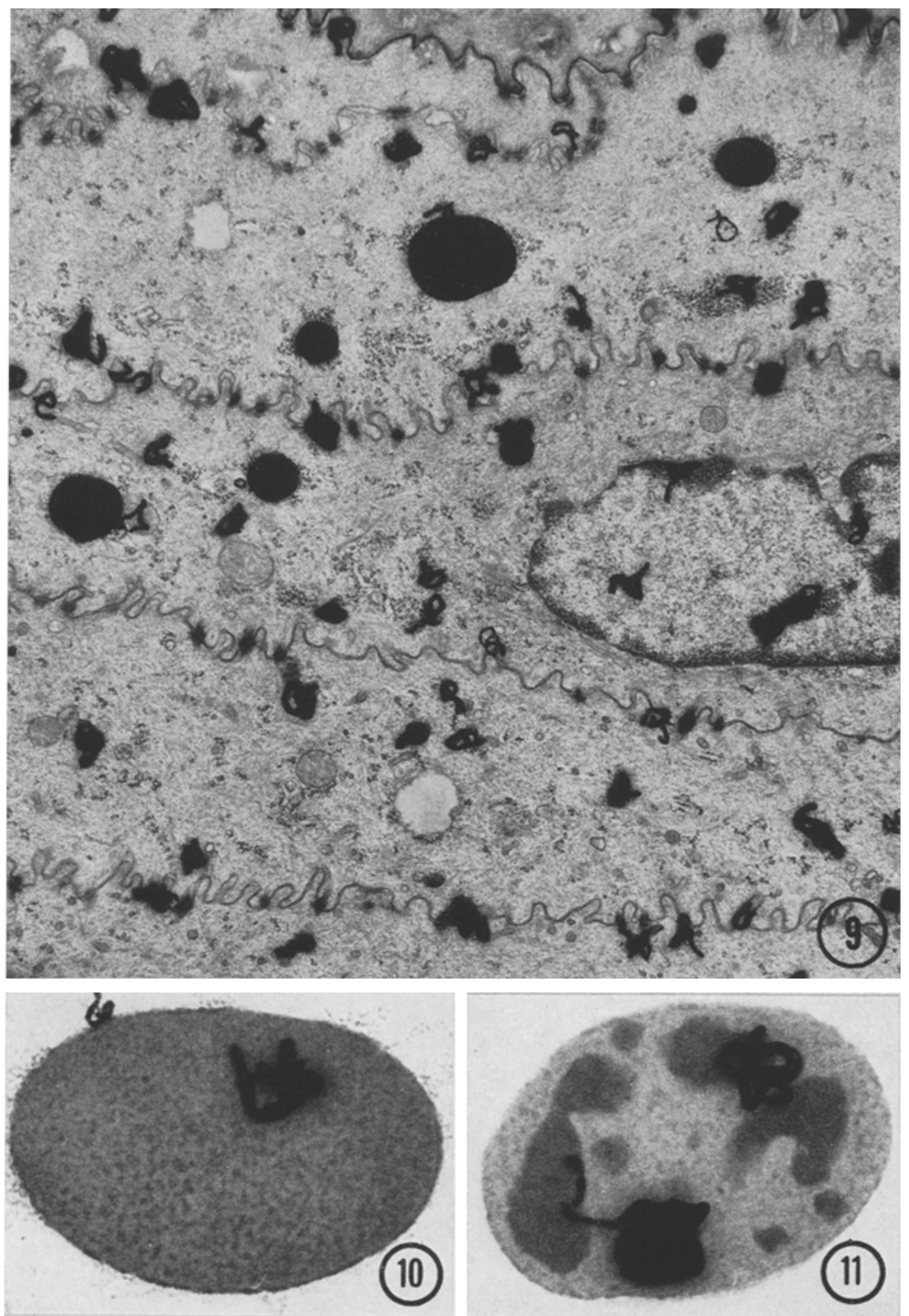

Fig. 9. EM autoradiograph of spinous cell 4 hours after proline- $\mathrm{H}^{3}$ administration. No preferential localization of proline- $\mathrm{H}^{3}$. Many grains associated with cellular periphery (see bottom portion of micrograph). For keratohyalin granule labelling see figures 11, 12. ×10800

Figs. 10-11. Two prints specifically exposed to indicate extent of labeling over keratohyalin granules. Usually one and, more rarely, two grains were located over the granules. Three and four grains have been observed in only four, large keratohyalin granules. The significance of the biphasic nature of the keratohyalin granules, is not understood. 11: $\times 18000 ; 12: \times 32400$ 


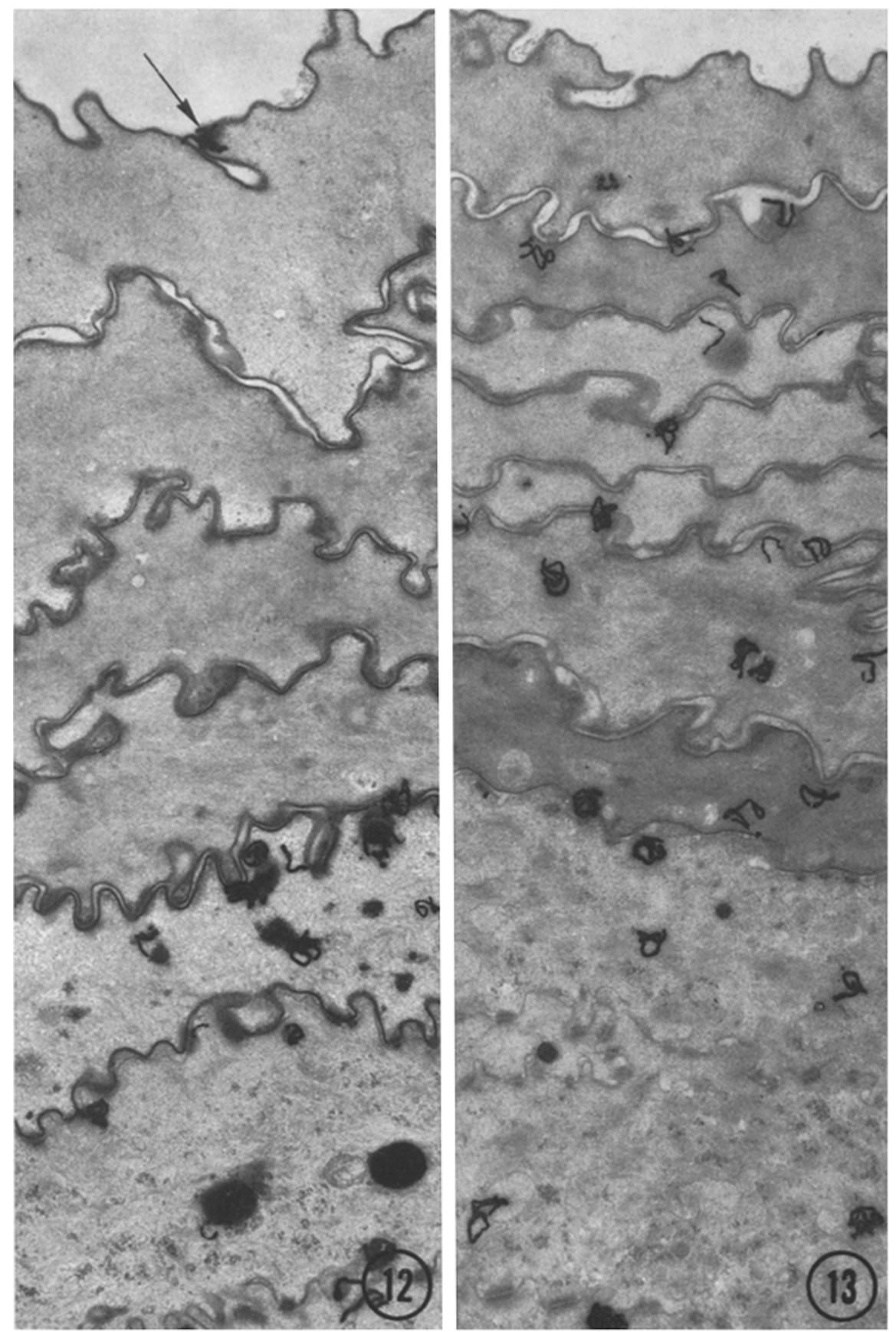

Fig. 12. Spinous epithelial cells, labelled 1 hour following proline- $\mathrm{H}^{3}$ administration. Keratinized epithelial cells not labelled except at the junction of epithelium with oral cavity (arrow). $\times 12000$

Fig. 13. Keratinized layer completely labelled 24 hours after proline- $\mathrm{H}^{3}$ administration. $\times 12000$ 
rates-however, all basal laminae studied by this technique appeared relatively long lived.

Excellent biochemical data exist (Kefalides, 1973; Spiro, 1973) which indicate that the basal lamina possesses several proline-containing substances including collagen. The inability of several studies to localize proline-containing substances in the basal lamina is probably due to the facts that the lamina was formed and intact (Nadol and Gibbins, 1970; this study) or that the connective tissue used in recombination experiments carried with it a pre-existing basal lamina (Berliner, 1969). The diluting effect of exogenous non-labelled proline can also decrease the extent to which newly synthesized basal laminae are labelled (Hay and Dodson, 1973).

Data derived from our study, while indicating keratohyalin contains proline, would argue in favor the of more recently reported 1 to $3 \%$ proline content (Tezulsa and Freedberg, 1972a; Ugel and Idler, 1972) rather than the $13 \%$ reported by Matoltsy and Matoltsy (1970). Our findings revealed a rather light labeling of individual KGH's. Additionally, we were unable to demonstrate that a majority of the total grains present within KHG-containing cells could be localized within KGH's as have Fukuyama and Epstein (1967) and Cox and Reaven (1967) using histidine- $H^{3}$. The rather large amount of histidine incorporated when compared with the amount of proline incorporated into KHG's further argues against a high proline content for KHG's as histidine is thought to represent between 3 (Tezuka and Freedborg, 1972a) and 10\% (Ugel and Idler, 1972) of the total amino acids in keratohyalin. In fact, labeling of KHG's was considerably less than the general labeling of the cell cytoplasm. This finding would appear to represent an additional argument against a high proline content for KHG's when one considers that the proline content of tonofilaments, a major component of KHG containing cells, is thought to be between 1 and $2 \%$ (Tezuka and Freedberg, 1972 b: Matoltsy, 1965). The role keratohyalin granules play in the process of keratinization remains to be demonstrated (Tezuka and Freedberg, $1972 \mathrm{a})$.

Our study indicates that stratified squamous epithelial cells synthesize a large number of proline containing substances which are widely distributed throughout both the cytoplasm and nucleus. Neither subjective inspection nor a variety of counting methods could localize the incorporated proline to either a single organelle or group of organelles. A temporal association of proline- $\mathrm{H}^{3}$ with ribosomes prior to association with other structures was prevented both by the dispersed nature of the ribosomes within the cytoplasm and the resolution afforded by techniques employed.

The distribution of proline- $\mathrm{H}^{3}$ in mouse lingual epithelium is essentially the same as that reported for newborn rat epidermis (Fukuyama and Epstein, 1966). Thus, it would appear that the stratified squamous epithelium from the two sources incorporates at least one amino acid in a similar fashion. Additionally, our study would support the finding (Bernstein et al., 1970) that amino acids pass easily across the basal lamina and have virtually free access to the cells in all epithelial strata. Our study also indicates that the rate of proline incorporation (protein synthesis ?) is much higher in stratified squamous epithelium than in the underlying connective tissue or striated muscle. 


\section{References}

Berliner, J.: The effects of the epidermis on the collagenous basement lamella of anuran larval skin. Develop. Biol. 20, 544-562 (1969)

Bernstein, I. A., Chakrabarti, S. G., Kumaroo, K. K., Sibrack, L. A.: Synthesis of protein in the mammalian epidermis. J. Invest. Derm. 55, 291-302 (1970)

Briggaman, R. A., Dalldorf, F. G., Wheeler, C. E.: Formation and origin of basal lamina and anchoring fibrils in adult human skin. J. Cell Biol. 51, 384-395 (1971)

Caro, L. G., Tubergen, R. P. van: High resolution autoradiography. I. Methods. J. Cell Biol. $15,173-188(1962)$

Cohen, A. M., Hay, E. D.: Secretion of collagen by embryonic neuroepithelium at the time of spinal cord-somite interaction. Develop. Biol. 26, 578-605 (1971)

Cox, A. J., Reaven, E. P.: Histidine and keratohyalin granules. J. invest. Derm. 49, 31-34 (1967)

Fukuyama, K., Epstein, W. L.: Epidermal keratinization: Localization of isotopically labeled amino acids. J. invest. Derm. 47, 551-560 (1966)

Fukuyama, K., Epstein, W. L.: Oltrastructural autoradiographie studies of keratohyalin granule formation. J. invest. Derm. 49, 595-604 (1967)

Fukuyama, F. K., Nakamura, T., Bernstein, I. A.: Differentially localized incorporation of amino acids in relation to epidermal keratinization in the newborn rat. Anat. Rec. 152, $525-535(1965)$

Hay, E. D., Dodson, J. W.: Secretion of collagen by corneal epithelium. I. Morphology of collagenous products produced by isolated epithelia grown on frozen-killed lens. J. Cell Biol. $57,190-214(1973)$

Kefalides, N. A.: Structure and biosynthesis of basement membranes. Int. Rev. Conn. Tissue Res. 6, 63-104 (1973)

Listgarten, M. A.: Normal development, structure, physiology and repair of gingival epithelium. Oral. Sci. Rev. 1, 3-68 (1972)

MacCallum, D. K.: In situ localization of proline in oral bacteria and on lingual epithelium. J. dent. Res. Jan.-Feb. issue, in press (1974)

Matoltsy, A. G.: Soluble prekeratin. In: Biology of the skin and hair growth, ed. by A. B. Lyne and B. F. Short. Sydney, Australia: Angus and Robertson, Ltd. 1965

Maltoltsy, A. G., Matoltsy, M. $\mathrm{N}_{\text {, }}$ : The chemical nature of keratohyalin granules in the epidermis. J. Cell Biol. 47, 593-603 (1970)

Matoltsy, A. G., Parakkal, P. F.: Keratinization. In: Ultrastructure of normal and abnormal skin, ed. by A. S. Zelickson. Philadelphia: Lea \& Febiger, 1967

Nadol, J. B., Gibbins, J. R.: Autoradiographic evidence for epithelial origin of glucose-rich components of the basement membrane (basal lamina) and basement lamella in the skin of Fundulus heteroclitus. Z. Zellforsch. 106, 398-411 (1970)

Parakkal, P. F.: Changes of the basal lamina during the hair growth cycle. J. Cell Biol. 40, $561-564(1969)$

Ross, M. H., Grant, L.: On the structural integrity of basement membrane. Exp. Cell Res. 50, $277-285(1968)$

Spiro, R. G.: Biochemistry of the renal glomerular basement membrane in diabetes mellitus. New Engl. J. Med. 288, 1337-1342 (1973)

Tezuka, T., Freedberg, g. M.: Epidermal structural proteins. I. Isolation and purification of keratohyalin granules of the newborn rat. Biochem. biophys. Acta (Amst.) 261, 402-417 (1972a)

Tezuka, T., Freedberg, I. M.: Epidermal structural proteins. II. Isolation and purification of tonofilaments of the newborn rat. Biochim. biophys. Acta (Amst.) 263, 382-396 (1972b)

Ugel, A. R., Idler, W.: Further characterization of bovine keratohyalin. J. Cell Biol. 52, $453-464$ (1972)

Walker, F.: Basement-membrane turnover in the rat. J. Path. 107, 119-121 (1972)

Donald K. MacCallum

5210 Dental Building

University of Michigan

Ann Arbor, Mi. 48104

USA 